\title{
Abstract
}

\section{Estimation of Out-of-Pocket Expenditure on COVID-19 \\ Management Among Patients Treated at Home, Iraq, 2020}

Falah Abdul kader Saeed ${ }^{1}$; Faris Lami ${ }^{2}$

\author{
${ }^{1}$ Iraqi Ministry of Health, Baghdad, Iraq \\ ${ }^{2}$ Ministry of Higher Education and Scientific Research, Baghdad, Iraq
}

\section{Corresponding Author:}

Falah Abdul kader Saeed

Iraqi Ministry of Health

Al-Rusafa

Baghdad

Iraq

Phone: 9647702526770

Email: falaah.abd1300a@comed.uobaghdad.edu.iq

\begin{abstract}
Background: There is a global consensus that the socioeconomic impact of the COVID-19 crisis has had a substantial effect on health programs and health insurance, with losses of jobs and rising prices causing growing poverty.

Objective: This study aims to estimate the out-of-pocket expenditure spent on the management of patients with COVID-19 exclusively treated at home.

Methods: A cross-sectional study was conducted, and data were collected from participating patients with COVID-19 in Iraq through snowball sampling by using a questionnaire. Enrollment occurred from November 1 to December 31, 2020, and excluded individuals who were entering the hospitals.

Results: Among 589 participating patients with COVID-19, 328 (55.7\%) were female. Female patients spent more than male patients to get cured of the illness; the mean amount of money spent by women was statistically higher than men (IQD 644,617 [US \$402] and IQD 461,653 [US \$307], respectively). The average total money expenditures spent was IQD 643,304 (US \$428; range IQD 505,096-5,595,000 [US \$336-US \$3730]) among patients exclusively treated at home. The average money spent by patients with inadequate monthly income (IQD 901,424 [US \$600], range IQD 220,000-5,260,000 [US \$140-US \$3500]) was significantly more than patients with adequate monthly income (IQD 613,252 [US \$400], range IQD 48,000-5,500,000 [US \$32-US \$3600]). Patients with COVID-19 (25.5\%) who had chronic diseases spent significantly more money (IQD 696,330 [US \$460]) than those without the chronic disease (IQD 625,185 [US \$416]).
\end{abstract}

Conclusions: Financial burdens affected the purchasing power and the economic situation on the management of patients with COVID-19 exclusively treated at home.

(iproc 2022;8(1):e36382) doi: $10.2196 / 36382$

\section{KEYWORDS}

poverty; out-of-pocket expenditure; chronic diseases; cross-section study

Edited by Y Khader; this is a non-peer-reviewed article. Submitted 12.01.22; accepted 17.01.22; published 04.02.22.

Please cite as:

Abdul kader Saeed F, Lami F

Estimation of Out-of-Pocket Expenditure on COVID-19 Management Among Patients Treated at Home, Iraq, 2020

iproc 2022;8(1):e36382

URL: https://www.iproc.org/2022/1/e36382

doi: $10.2196 / 36382$

PMID: 
CFalah Abdul kader Saeed, Faris Lami. Originally published in Iproceedings (https://www.iproc.org), 04.02.2022. This is an open-access article distributed under the terms of the Creative Commons Attribution License (https://creativecommons.org/licenses/by/4.0/), which permits unrestricted use, distribution, and reproduction in any medium, provided the original work, first published in Iproceedings, is properly cited. The complete bibliographic information, a link to the original publication on https://www.iproc.org/, as well as this copyright and license information must be included. 